\section{Representações sociais do medicamento genérico por farmacêuticos: determinação dos sistemas central e periférico}

\author{
Social representations of generic drugs \\ by pharmacists: determination of the central \\ and peripheral representational systems
}

Maria Cleide Ribeiro Dantas de Carvalho 1 Horácio Accioly Jr. 1

Fernanda Nervo Raffin 1

Mariana Nunes Campos 1

Marcelle Marie Caldas Cruz 1

Markênia Kélia Santos Alves 1

\footnotetext{
1 Departamento de Farmácia, Universidade Federal do Rio Grande do Norte, Natal, Brasil.

Correspondência M. C. R. D. Carvalho Laboratórios

Interdisciplinares de Estudos em Representações Sociais,

Departamento de Farmácia, Universidade Federal do Rio Grande do Norte. Rua Abdon Nunes 871, apto. 602, Natal, RN 59014-540, Brasil. cleidecarvalho@hotmail.com
}

\begin{abstract}
This article aimed to identify the central and peripheral systems in social representations of generic drugs by pharmacists, as well as their social and economic profile, thereby establishing potential mechanisms for improving policies for generic drugs in Brazil. The data collection instruments were a questionnaire and a word association test, the inductive cue of which was the term "generic drug". Data collected through the questionnaire produced a profile of pharmacists in the city of Natal, Rio Grande do Norte State, and key information related to the theme. Data analysis for the word association test used Evoc 99 software while content analysis used Bardin, thereby identifying the central system in social representations of generic drugs, consisting of the categories price, quality, and credibility, while the peripheral system consisted of the categories pharmaceutical care, social impact, novelty, accessibility, options, and interchangeability.
\end{abstract}

Generic Drugs; Pharmacists; Pharmaceutical Services

\section{Introdução}

Na implementação de políticas nacionais de medicamentos recomendadas pela Organização Mundial da Saúde (OMS), vários países no mundo, atualmente, desenvolvem duas grandes linhas. A primeira é fundamental e envolve a promoção de medicamentos essenciais como a melhor abordagem sob o ponto de vista de saúde; essa abordagem é complementada pelo incentivo do uso de medicamentos genéricos de qualidade como estratégia importante para fomentar tanto preços acessíveis quanto o próprio acesso aos medicamentos.

Apesar de se entrar no século XXI dispondo de um avanço tecnológico que pode ser capaz de conquistas fantásticas, direitos básicos como a garantia de medicamentos essenciais aos tratamentos médicos, ainda são bens muito distantes de serem alcançados, pois um terço da população mundial não tem ainda acesso aos medicamentos de que necessita para uma boa saúde 1 . Um dos objetivos da política de medicamentos debatidos no Seminário Andino sobre Políticas de Medicamentos, realizado em Cartagena, Colômbia, resume com propriedade o sentimento estabelecido anteriormente, quando afirma que: " a disponibilidade e o acesso aos medicamentos constituem parâmetros que permitem medir a qualidade dos serviços de saúde e constituem indicadores sociais de justiça e eqüidade na distribuição das riquezas de uma nação" 2. 
No Brasil, a discussão sobre o medicamento genérico foi deflagrada em 1991, pelo Projeto de Lei 2.022 apresentado à Câmara dos Deputados pelo Deputado Federal Eduardo Jorge (PT-SP). Após uma longa tramitação e depois de receber várias emendas e substitutivos, esse projeto foi aprovado pelo Congresso Nacional e sancionado pelo então Presidente da República Fernando Henrique Cardoso, transformando-se na Lei 9.787 de 10 de fevereiro de 1999 3, conhecida como "Lei dos Genéricos”, a qual instituiu o medicamento genérico no Brasil, pondo fim a uma polêmica que se arrastou por quase uma década. A Agência Nacional de Vigilância Sanitária (ANVISA) tem editado uma série de normas (resoluções e portarias), a fim de viabilizar o registro, a produção, a prescrição e a dispensação do medicamento genérico, norteando todo o processo de implementação da política desses medicamentos no Brasil.

O Brasil tem empreendido importantes esforços para melhorar o acesso aos medicamentos, promovendo políticas de saúde mais consistentes, cujo objetivo maior é atingir com mais eficiência uma parcela cada vez maior da população. As estratégias e políticas de garantias de saúde passam pela aquisição de produtos farmacêuticos e a política de medicamentos genéricos é uma dessas táticas.

O mercado brasileiro de medicamentos genéricos corresponde a 7,0\% do mercado nacional em unidades e 5,0\% em valor 4 . A necessidade de aumentar essas cifras para permitir um maior acesso da população aos tratamentos médicos, assim como diminuir custos, incita a investigação das possíveis causas que podem estar obstando a concretização dessa política no país.

O Brasil é, atualmente, o quinto maior produtor de medicamentos (com estratégia nos genéricos) do mundo com um faturamento anual de cerca de 6 bilhões de dólares. Os genéricos participam com $6,6 \%$ desse valor 5 . Além disso, segundo a revista The Economist, o Brasil ocupa o nono lugar mundial em consumo de medicamentos per capita 4 .

A política de genéricos objetiva uma maior racionalidade no uso de medicamentos, bem como estimula a concorrência por intermédio da qual os consumidores terão disponíveis produtos intercambiáveis de diferentes preços, respeitando-se a decisão do não intercâmbio do profissional prescritor. É previsível que a referida competição ocasione a redução dos preços dos medicamentos, trazendo então benefícios a todos os segmentos envolvidos na cadeia de produção, controle, comercialização e, especialmente, o consumo.

O impacto da política de medicamentos genéricos no setor farmacêutico não deve ser buscado apenas na dimensão dos preços. O surgimento dos genéricos deve ser uma oportunidade para o planejamento e a execução de uma gradativa transformação na assistência e na atenção farmacêutica, uma vez que o papel do farmacêutico na cadeia de implantação dessa política de medicamentos é essencial.

A política de medicamentos genéricos no Brasil encontra-se no início do seu processo de implantação, e, como tal, necessita de que se conheça em profundidade os obstáculos reais ao seu pleno estabelecimento, elaborando-se estratégias eficientes que visem ultrapassar esses empecilhos para que a mesma alcance pleno êxito em âmbito social. O conhecimento das representações sociais do medicamento genérico pelos farmacêuticos poderá demonstrar quais os obstáculos que se colocam contra a consolidação dessa política de medicamentos no país, auxiliando o governo no estabelecimento de estratégias que objetivem contornálos, propiciando a sua melhor adequação às necessidades do setor.

Considerando-se as características pelas quais se contextualizou o objeto do estudo a ser desenvolvido, optou-se pela escolha da Teoria das Representações Sociais (TRS) 6 e da Teoria do Núcleo Central (TNC) 7 como suporte teórico-metodológico a ser utilizado.

Segundo Jodelet 8 (p. 36), representações sociais são "uma forma de conhecimento, socialmente elaborada e partilhada, que tem um objetivo prático e concorre para a construção de uma realidade comum a um conjunto social". A compreensão dessa realidade comum no grupo social aqui estudado (farmacêuticos) é uma maneira de serem captados detalhes da realidade vivenciada por esse grupo em relação ao medicamento genérico, servindo de base para a implementação de futuras estratégias que visem à melhoria da implantação da política de medicamentos genéricos no país em relação a esse grupo.

\section{Metodologia}

\section{Sujeitos}

Os sujeitos dessa pesquisa foram 72 farmacêuticos inscritos no Conselho Regional de Farmá- 
cia do Rio Grande do Norte (CRF/RN), responsáveis técnicos por farmácias e/ou drogarias da cidade do Natal, Estado do Rio Grande do Norte, no período de agosto a outubro de 2002.

Para o estabelecimento de uma amostra significativa com nível de confiança de 95\%, aplicou-se a fórmula da população finita 9,10,11.

\section{Instrumento de coleta de dados}

Como instrumentos de coleta de dados foram utilizados um questionário, com questões fechadas que tinham a função de promover o levantamento de dados demográficos dos farmacêuticos incluídos no estudo, como também de sondar algumas questões pertinentes ao tema e ao teste de associação ou evocação livre de palavras.

O teste de associação ou evocação livre de palavras se constitui num tipo de investigação aberta que se estrutura na evocação de respostas dadas com base num estímulo indutor. As diversas evocações ocorridas, uma vez listadas, irão compor um conjunto heterogêneo de unidades semânticas, no dizer de Bardin 12, o que exige um trabalho de classificação para facilitar as análises descritivas e explicativas, necessárias para chegar às representações do objeto considerado. Na análise do teste de associação, as evocações são classificadas em categorias nas quais os critérios são orientados pela dimensão da análise em questão 12 .

Como estímulo indutor foram utilizadas as palavras medicamento genérico. Para cada farmacêutico foi solicitada a evocação de três palavras. Tal procedimento baseou-se na estratégia de acesso ao Núcleo Central de Vergès apresentado por Sá 13. A análise do teste foi baseada na TNC 13, na análise de conteúdo preconizada por Bardin 12, como também pelo programa EVOC 99.

As evocações livres foram tratadas utilizando-se o programa EVOC 99, que facilita o processo ao calcular todas as Ordens Médias de Evocação (OME), as quais posteriormente foram agrupadas em categorias estabelecidas em razão dos caracteres comuns desses elementos.

\section{Resultados}

\section{Questionários}

A análise de dados colhidos pelos questionários permitiu que fosse traçado um perfil da classe farmacêutica em Natal que demonstrou as seguintes características: $75,00 \%$ são do sexo feminino com média de idade de 36 anos \pm 11,8 e $31,90 \%$ são casadas.
Quanto à formação acadêmica os dados revelaram que $80,55 \%$ dos farmacêuticos foram graduados na Universidade Federal do Rio Grande do Norte (UFRN), com 51,38\% de indivíduos com a habilitação farmacêutico bioquímico analista clínico, atuando como responsáveis técnicos por estabelecimentos farmacêuticos. Desse valor, observa-se que as mulheres representam $43,05 \%$. As outras habilitações compreendem $29,16 \%$ de farmacêuticos e $19,44 \%$ de farmacêuticos industriais.

A pós-graduação ainda é muito tímida entre os responsáveis técnicos, representando apenas $30,55 \%$, sendo a especialização a que representa a maior proporção desse montante $(23,61 \%)$, seguida pelo mestrado $(5,55 \%)$ e doutorado $(1,38 \%)$.

Com relação à faixa salarial, os dados revelaram que $47,22 \%$ dos farmacêuticos recebem entre 4 a 6 salários mínimos, como está demonstrado na Tabela 1 . O acordo realizado entre o Sindicato dos Farmacêuticos do Rio Grande do Norte e os proprietários de farmácias sobre a remuneração do farmacêutico estabeleceu os valores de R\$1.200,00 para oito horas e $\mathrm{R} \$ 600,00$ para quatro horas diárias de trabalho, incluída, pois, na faixa salarial de 4 a 6 salário mínimos. Os farmacêuticos com renda superior a essa faixa salarial correspondem a 50,00\% da amostra; desses, 25,00\% têm carga horária superior aos limites estabelecidos no acordo. Os farmacêuticos com renda inferior a esses valores representam apenas $2,77 \%$ da amostra.

Outro item levantado no questionário foi quanto aos motivos que levaram à escolha da profissão farmacêutica. Os dados demonstraram que em $41,66 \%$ o que motivou a escolha foi a vocação, em seguida a influência familiar $(19,44 \%)$, o fato de terem sido aprovados em segunda opção no vestibular (18,05\%), o mercado de trabalho $(11,11 \%)$ e outras causas não reveladas $(9,72 \%)$.

Com relação à satisfação com a profissão, $98,62 \%$ se mostraram satisfeitos em graus que variam de muito a regularmente satisfeito. Os motivos alegados para tal satisfação foram realização pessoal $(44,44 \%)$ e as atividades exercidas na farmácia (45,83\%). Entretanto, 65,27\% alegaram o salário como fonte de insatisfação.

Quanto às questões pertinentes ao propósito do presente estudo, detectou-se que $97,22 \%$ acreditam que os medicamentos genéricos são de qualidade e, depois da sua introdução no mercado, $62,50 \%$ dos farmacêuticos sentiram alguma mudança nas atividades exercidas na farmácia. Essas mudanças se caracterizaram pelos seguintes aspectos: $51,11 \%$ afirmaram que os clientes passaram a pedir mais informações, 
$15,55 \%$ sentiram que o farmacêutico passou a ser mais reconhecido pelos clientes, $15,55 \%$ referiram a necessidade da presença mais efetiva do farmacêutico na farmácia, $6,66 \%$ mencionaram o intercâmbio responsável por essas mudanças, $2,22 \%$ aludiram a necessidade de estudar mais para poder dar melhores informações aos clientes, $2,22 \%$ fizeram referência a um aumento de fiscalização na farmácia e $6,66 \%$ não informaram os motivos das mudanças.

\section{Teste de associação de palavras}

O teste de evocação resultou em 216 unidades de significado; de cada uma delas foi calculada a OME 13, e em seguida essas unidades de significado foram agrupadas em 11 categorias como mostra a Tabela 2.

De acordo com Bardin 12, a categorização é uma operação de classificação de elementos constitutivos de um conjunto. As categorias reúnem um grupo de elementos com caracteres comuns, sob um título genérico.

Estabeleceu-se também a média das OME (MOME), em 2,2962, e a Freqüência Média (FM) das palavras evocadas em 19,636.

O esquema figurativo que está demonstrado na Figura 1 foi baseado num gráfico de dispersão em que o eixo das abscissas ( $\mathrm{x}$ ) corresponde aos valores referentes as OME e o eixo das ordenadas (y) aos valores da freqüência. Desse modo, cada evocação corresponde a um ponto no gráfico, o que sugere uma correlação positiva entre as variáveis, segundo o modelo proposto por Vieira 14 e Beaufils 15. Ao se deslocar o eixo para o ponto que representa o valor de suas médias, estabelece-se os quatro quadrantes que estão representados no esquema figurativo.

As evocações que figuram no quadrante superior esquerdo são as que mais provavelmente fazem parte do núcleo central, as que estão no quadrante inferior direito pertencem ao sistema periférico, enquanto as demais são consideradas intermediárias e, no estudo em questão, não se situam bem definidas.

“As representações sociais são ao mesmo tempo estáveis e móveis, rígidas e flexíveis, consensuais, mas marcadas por fortes diferenças

Tabela 1

Correlação entre faixa salarial e horas diárias trabalhadas de 72 farmacêuticos responsáveis técnicos por farmácias e/ou drogarias na cidade do Natal, Rio Grande do Norte, Brasil, agosto/outubro de 2002.

\begin{tabular}{lccccc}
\hline $\begin{array}{l}\text { Horas diárias } \\
\text { trabalhadas }\end{array}$ & 1-3 SM & \multicolumn{2}{c}{ Faixa salarial (\%) } & Total (\%) \\
\hline 4 & 1 & 4 & $7-8 \mathrm{SM}$ & $>8 \mathrm{SM}$ & \\
6 & - & 5 & 1 & 2 & $10(13,88)$ \\
8 & 1 & 22 & 5 & 2 & $8(11,11)$ \\
10 & - & 1 & - & 10 & $11(15,27)$ \\
12 & - & 2 & 2 & 3 & $7(9,72)$ \\
Total & $2(2,77)$ & $34(47,22)$ & $11(15,27)$ & $25(34,72)$ & $72(100,00)$ \\
\hline
\end{tabular}

$\mathrm{SM}$ = salário mínimo (valor na época da coleta dos dados: $\mathrm{R} \$ 200,00$ ).

Associação das palavras medicamento genérico, por ordem de evocação, de 72 farmacêuticos em Natal, Rio Grande do Norte, Brasil, agosto/outubro de 2002.

\begin{tabular}{|c|c|c|c|c|c|}
\hline Categorias & 1ạ Evocação & 2ạ Evocação & 3ạ Evocação & Freqüência & OME \\
\hline 1 Preço & 30 & 13 & 10 & 53 & 1,622 \\
\hline 2 Equivalência & 8 & 6 & 3 & 17 & 1,705 \\
\hline 3 Qualidade & 16 & 22 & 6 & 44 & 1,772 \\
\hline 4 Credibilidade & 15 & 12 & 16 & 43 & 2,023 \\
\hline 5 Medicamento & 1 & 3 & 2 & 6 & 2,166 \\
\hline 6 Assistência farmacêutica & 1 & 1 & 4 & 6 & 2,500 \\
\hline 7 Impacto social & 1 & 4 & 7 & 12 & 2,500 \\
\hline 8 Novidade & 0 & 3 & 4 & 7 & 2,571 \\
\hline 9 Acessibilidade & 0 & 6 & 9 & 15 & 2,600 \\
\hline 10 Opções & 0 & 2 & 8 & 10 & 2,800 \\
\hline 11 Intercambialidade & 0 & 0 & 3 & 3 & 3,000 \\
\hline Total & 72 & 72 & 72 & 216 & \\
\hline
\end{tabular}

OME = ordem média de evocação. 
Figura 1

Esquema figurativo: identificação dos possíveis elementos do núcleo central das representações sociais do medicamento genérico por farmacêuticos da cidade do Natal, Rio Grande do Norte, Brasil, agosto/outubro de 2002.

\begin{tabular}{|c|c|c|c|}
\hline \multicolumn{2}{|c|}{ OME $<2,2962$ e $F>19,636$} & \multicolumn{2}{|l|}{ OME $<2,2962$ e $F>19,636$} \\
\hline Preço (53) & 1,622 & & \\
\hline Qualidade (44) & 1,772 & & \\
\hline Credibilidade (43) & 2,023 & & \\
\hline \multicolumn{2}{|c|}{ OME $<2,2962$ e $F>19,636$} & \multicolumn{2}{|l|}{ OME $<2,2962$ e $F>19,636$} \\
\hline Equivalência (17) & 1,705 & Assistência farmacêutica (6) & 2,500 \\
\hline \multirow[t]{4}{*}{ Medicamento (6) } & 2,166 & Impacto social (12) & 2,500 \\
\hline & & Novidade (7) & 2,571 \\
\hline & & Opções (10) & 2,800 \\
\hline & & Intercambialidade (3) & 3,000 \\
\hline
\end{tabular}

Adaptado de Vergès, apud Tura 29 za de seus elementos periféricos. Mas ela só se transforma radicalmente (muda de significação) quando o próprio núcleo central é posto em questão 16 .

Em torno do núcleo central, organizam-se os elementos periféricos da representação que, provendo a "interface entre a realidade concreta e o sistema central" 7 (p. 79), atualizam e contextualizam as determinações normativas do núcleo central. O sistema periférico é, diferentemente do central, flexível e evolutivo sendo, portanto, mais sensível ao contexto imediato. Logo, é nele que devem se concentrar as estratégias que visem interferir no núcleo das representações sociais de um determinado grupo.

\section{- Sistema central}

(a) Preço

A categoria preço foi a que mais se destacou no teste de associação de palavras, compreendendo 13 palavras que foram evocadas 53 vezes. Nessa categoria foram agrupadas as seguintes evocações: preço, preço bom, preço barato, preço baixo, bom preço, menor preço, barato, mais barato, custo, custo menor, baixo custo, economia e caro.

Ainda que o impacto da política de medicamentos genéricos no setor farmacêutico não deve ser buscada apenas na dimensão dos preços, este foi, sem dúvida, o componente mais forte da representação.

A forma de comercialização dos medicamentos genéricos retira dos representantes a função de fator primordial no processo de difusão do medicamento e a repassa ao farmacêutico (teoricamente) e ao balconista (na realidade) e introduz a competição em preços no mercado farmacêutico, pois a farmácia, para aumentar as suas margens de lucro, tentará comprar o medicamento com o preço menor 17.

A década de 90 apresenta algumas peculiaridades em termos de evolução dos principais elementos do mercado farmacêutico: um aumento do faturamento associado a uma diminuição das quantidades vendidas. Tal episódio só poderia se estabelecer com um aumento efetivo dos preços. Some-se a isso o fato de que a população brasileira nessa década aumentou cerca de 15 milhões de pessoas, tornando o decréscimo do consumo de medicamentos uma questão social relevante 17 .

O preço dos medicamentos sempre foi uma preocupação constante dos diferentes gover nos brasileiros por achar que eles são uma barreira ao acesso aos medicamentos, muito embora a própria Comissão Parlamentar de In- 
quérito (CPI) dos Medicamentos reconheça que o acesso está muito mais relacionado à renda da população do que propriamente ao preço 18 .

No entanto, não se pode descartar que o preço é um dos importantes fatores que dificultam tal acesso, daí a constante preocupação com seu controle e monitoramento, bastando para isso que se analise a recente evolução da política de preços de medicamentos no Brasil, que pode ser dividida em vários períodos: (1) décadas de 70-80 quando o controle era realizado pelo extinto Conselho Interministerial de Preços (CIP); (2) anos de 1990-1992 com a política dos Planos Collor I e II; (3) anos 1993-1994 período de acompanhamento informal que antecedeu o Plano Real; e (4) período mais recente, em que ocorreu a liberação gradual dos preços 18. Atualmente, o monitoramento e o controle de preço dos medicamentos são realizados pela Câmara de Medicamentos criada em dezembro de 200019.

Os diversos documentos colhidos na CPI dos Medicamentos e as investigações realizadas revelaram a prática de preços excessivos. Entre outros fatores, as elevações de preços observados no período de 1993 a 1999 se deveram a distorções geradas pela Portaria no 37 de 11 de maio de 1992 20. Essa portaria determina no parágrafo 1o do seu artigo 2o, que o preço máximo ao consumidor para os produtos farmacêuticos (preço de varejo) da linha humana seja calculado mediante divisão do preço estabelecido pelas unidades produtoras (preço do fabricante) por 0,7 , e que o mesmo deve ser único em todo o território nacional. Para efeito do preço de varejo, são somados ao preço de fábrica os custos para financiar as vendas do laboratório, as suas despesas com fretes, os seus gastos com tributos, além dos descontos concedidos às distribuidoras. Esse valor agregado é dividido por 0,7 , resultando o chamado preço máximo de tabela (preço de varejo), garantindo a margem de $30,00 \%$ da farmácia.

Dessa forma, essa portaria estabelecia uma acomodação nos diversos níveis do mercado, cujos efeitos se assemelhavam aos de um cartel, além de prefixar as margens de preços para as distribuidoras e farmácias, num estímulo a que se superestimasse custos e preços. Em decorrência desses fatos, a CPI recomendou a extinção da referida portaria 18 .

Em resposta às recomendações e conclusões da CPI dos Medicamentos foi editada a Medida Provisória no 2.063 de 18 de dezembro de 2000 19, a Medida Provisória no 2.138-2 de 28 de dezembro de 2000 21, que por sua vez foi reeditada duas vezes e finalmente convertida na Lei no 10.213 de 27 de março de 2001 22, a qual instituiu a Fórmula Paramétrica de Reajustes de Preços de Medicamentos (FPR) e criou a Câmara de Medicamentos, responsável por julgar, dentre outras atribuições, os pedidos de reajustes extraordinários de preços de medicamentos. Por sua vez, a Câmara de Medicamentos desde a sua criação tem editado várias resoluções reajustando os preços dos medicamentos.

Recentemente a Medida Provisória no 123, de 26 de junho de 2003 23, estabeleceu o reajuste anual de preços para os medicamentos e criou a Câmara de Regulação do Mercado de Medicamentos (CMED). Essa câmara, composta por representantes dos ministérios da Saúde, Justiça, Fazenda e Casa Civil tem, entre suas funções, a regulação do mercado e o estabelecimento de critérios para a definição e ajuste de preços - inclusive para novas apresentações de medicamentos.

De acordo com dados do Ministério da Saúde 24 , o perfil do consumidor brasileiro é constituído por três classes: a primeira representa $15,00 \%$ da população, tem renda acima de dez salários mínimos e consome $48,00 \%$ do mercado total de medicamentos; a segunda é formada por $34,00 \%$ da população, tem renda em torno de quatro a dez salários mínimos e consome 36,00\% do mercado; e a terceira é constituída por $51,00 \%$ da população com renda de zero a quatro salários mínimos e consome apenas $16,00 \%$ do mercado.

Para a classe de renda elevada o preço tem pouca influência no consumo, pois essa população sempre usará os medicamentos que forem receitados, com preferência pelos de última geração tecnológica.

Os consumidores inseridos na classe intermediária de renda, sobretudo aqueles que constituem os patamares inferiores dessa classe, certamente são os mais beneficiados com a política de medicamentos genéricos e para eles o preço é um dos fatores que decide o acesso aos medicamentos. Para esse segmento da população as políticas que permitem uma redução de preços podem ter um efeito imediato no consumo de medicamentos.

A população de baixa renda revela um padrão de consumo em que aquilo que define o acesso ao medicamento não é o preço e sim a renda, visto que, mesmo com uma queda significativa dos preços, a renda é tão baixa que torna seu consumo praticamente impossível.

Por mais que não atinja todas as classes definidas no perfil do consumidor brasileiro, o preço é indiscutivelmente um fator importante no ciclo da comercialização. Assim sendo, é amplamente compreensível que ele se constitua no cerne da representação social do medicamento 
genérico, uma vez que, diariamente, a classe farmacêutica lida no seu estabelecimento comercial com eles, sentindo de perto o drama dos menos favorecidos economicamente e torcendo para que o acesso ao medicamento não seja privilégio de alguns, mas direito de todos.

\section{(b) Qualidade e credibilidade}

No teste de evocação de palavras, qualidade e credibilidade no medicamento genérico foram os outros constituintes do núcleo central da representação. Essas categorias foram detectadas pelas seguintes evocações: qualidade, boa qualidade, garantia de qualidade, bom (para a categoria qualidade) e confiança, credibilidade, confiável, confiabilidade, segurança (para a categoria credibilidade).

Nos questionários, a resposta dada à questão relacionada à qualidade dos genéricos demonstrou que $97,00 \%$ dos farmacêuticos acreditam que o genérico é um medicamento de qualidade, justificando, assim, ser esse um dos componentes do núcleo central.

De acordo com a legislação em vigor " $m e$ dicamento genérico é um medicamento similar a um produto de referência que se pretende com este ser intercambiável, geralmente produzido após a expiração ou renúncia patentária ou de outros direitos de exclusividade, comprovada a eficácia, segurança e qualidade" (destaque nosso) ${ }^{3}$. A definição legal afirma a que o medicamento genérico deve ter a sua qualidade comprovada e de acordo com os dados colhidos nesses dois instrumentos de coleta de dados a grande maioria da classe farmacêutica acredita na qualidade apropriada desse tipo de medicamento.

O descrédito com relação à qualidade do genérico, demonstrado em apenas $3,00 \%$ dos farmacêuticos pesquisados, tanto pode ser resultado de reclamações feitas ao farmacêutico sobre a ineficácia de alguns produtos genéri cos por pacientes no balcão da farmácia, quanto pelos resultados de algumas pesquisas que questionam a biodisponibilidade e bioequivalência do produto genérico com o de referência, como é o caso dos trabalhos de Silva \& Santana 25, Even-Adin et al. 26, Castanedo-Cázares et al. 27, Besag 28, dentre outros.

\section{- Sistema periférico}

Os componentes do sistema periférico detectados e categorizados no presente estudo como assistência farmacêutica, impacto social, novidade, acessibilidade, opções e intercambialidade refletem a contextualização imediata do genérico e podem ser usados para indiretamente interferir no núcleo central, na tentativa de se alterar o cerne dessa representação social, dirimindo os obstáculos com relação à aceitação desse tipo de medicamento pela classe farmacêutica. Essas categorias foram detectadas pelas seguintes evocações: assistência farmacêutica, atenção farmacêutica, mais informação, cliente, dificulta a "empurroterapia" (para a categoria assistência farmacêutica), ajuda a população, saúde para o povo, popular, sociedade, benefício ao cliente, alternativa para a população, saúde pública (para a categoria impacto social), inovação, atrativo, novidade (para a categoria novidade), mais acesso, acessibilidade, muito procurado, facilidade de compra, acessível, acesso fácil, difícil acesso (para a categoria acessibilidade), mais opção, variedade, liber dade de escolha (para a categoria opções), e intercambialidade e segurança na troca (para a categoria intercambialidade).

Os dados levantados nos questionários também referem essas categorias detectadas no teste de associação de palavras, como o item assistência farmacêutica que o questionário captou como a necessidade da presença do farmacêutico na farmácia e o fato do cliente solicitar mais informações ao farmacêutico. Com relação à categoria opção, o questionário aponta a liberdade de escolha pelo cliente como outra mudança sentida na farmácia após a introdução da política de genéricos.

\section{Conclusões}

As representações sociais do medicamento genérico para os farmacêuticos da cidade de $\mathrm{Na}$ tal têm um núcleo central alicerçado no preço, qualidade e credibilidade, enquanto o sistema periférico é constituído pelas categorias assis tência farmacêutica, impacto social, novidade, acessibilidade, opções e intercambialidade.

O trinômio preço-qualidade-credibilidade se constitui naquilo que é consensual no grupo avaliado, definida a sua homogeneidade em relação ao medicamento genérico. As categorias assistência farmacêutica, impacto social, novidade, acessibilidade, opções e intercambialidade representam a heterogeneidade do gru po, tendo um caráter evolutivo, são mais sensíveis às novas informações ou eventos suscetíveis de colocar em questão o núcleo central.

A determinação dos sistemas central e periférico das representações sociais do medicamento genérico por farmacêuticos, proporciona uma importante ferramenta na elaboração de estratégias que visem incrementar a política 
de medicamentos genéricos para essa categoria, pelo fato de permitir um maior conhecimento do imaginário dessa classe em relação ao objeto em tela.

O fato de o sistema periférico ser mais suscetível às mudanças, permitindo uma maior flexibilidade e evolução no contexto em que o genérico está inserido aponta para a utilização de táticas que priorizem as categorias determinadas nesse sistema, criando condições mais favoráveis à ampla aceitação do genérico para os farmacêuticos e permitindo a ampla instalação dessa política junto ao segmento farmacêutico.

Para Abric 7, o sistema central é essencialmente normativo, enquanto o sistema periférico é funcional. Isto quer dizer que é graças a ele que a representação pode se ancorar na realidade do momento. Essa compreensão é importante quando o que se busca é descobrir caminhos possíveis para desencadear modificações das representações sociais de um grupo,

\section{Resumo}

O artigo objetiva determinar os sistemas central e periférico das representações sociais do medicamento genérico por farmacêuticos, assim como o perfil sócioeconômico desse grupo, estabelecendo dessa forma mecanismos que poderão ser utilizados no aprimoramento da política desse tipo de medicamento no Brasil. Os instrumentos de coleta de dados utilizados foram um questionário e um teste de associação de palavras cujo estímulo indutor foram as palavras medicamento genérico. Os dados levantados pelo questionário permitiram que se traçasse um perfil da classe farmacêutica em Natal, Rio Grande do Norte, além de também colher alguns dados pertinentes ao tema. A análise dos dados do teste de associação de palavras foi realizada com o auxílio do programa EVOC 99 e da análise de conteúdo preconizada por Bardin, o que permitiu que se estabelecesse o sistema central das representações sociais do medicamento genérico composto pelas categorias preço, qualidade e credibilidade e o sistema periférico constituído pelas categorias assistência farmacêutica, impacto social, novidade, acessibilidade, opções e intercambialidade.

Medicamentos Genéricos; Farmacêuticos; Serviços Farmacêuticos por se entender que as elas representam um obstáculo ao desenvolvimento de práticas sociais alternativas às vigentes.

Dessa forma, a efetivação de políticas que premiem a assistência farmacêutica, permitindo que o farmacêutico esteja cada vez mais presente na farmácia, estabelecendo uma relação mais efetiva com o paciente, assim como estratégias que busquem ampliar uma maior variabilidade de medicamentos genéricos nas farmácias, permitindo uma maior oferta desses medicamentos à população, podem ser instrumentos importantes para o sucesso dessa política no Brasil. Além disso, o estabelecimento do perfil sócio-econômico dos farmacêuticos, que constituem o grupo avaliado no presente estudo, também se constitui numa importante ferramenta a ser considerada na implementação de estratégias que objetivem uma melhor agilidade na implementação da política de medicamentos genéricos no país.

\section{Colaboradores}

M. C. R. D. Carvalho elaborou o artigo. F. N. Raffin contribuiu com orientação na área do medicamento genérico. $\mathrm{H}$. Accioly Jr. contribuiu com orientação na área das representações sociais. M. N. Campos, M. M. C. Cruz e M. K. S. Alves contribuíram na aplicação dos questionários e dos testes de associação livre de palavras. 


\section{Referências}

1. Brundtland GH. Declaração à Comissão Parlamentar de Inquérito sobre Medicamentos. http: //www.who.int/director-general/speeches / 2000/20000404_brasilia.pt.html (acessado em 07/ Ago/2001).

2. World Health Organization. Pharmaceutical policy of the Andean Sub-region pharmaceutical. http://www.who.int/medicines/library/dap/who -dap-93-7/who-dap-93-7.htm (acessado em 03/ Jun/2002).

3. Brasil. Lei no 9.787 de 10 de fevereiro de 1999. Altera a lei no 6.360, de 23 de setembro de 1976, que dispõe sobre a vigilância sanitária, estabelece o medicamento genérico, dispõe sobre a utilização de nomes Genéricos em produtos farmacêuticos e dá outras providências. Diário Oficial União 1999; 11 fev.

4. Sánchez CE. Um panorama da indústria de genéricos. Fármacos \& Medicamentos 2002; 16:44-6.

5. Fuck FD. Os genéricos conquistam o mundo. Especial Genéricos 2001; 8:8-11.

6. Moscovici S. A representação social na psicanálise. Rio de Janeiro: Zahar Editores; 1978.

7. Abric J-C. L'organization interne des représentations sociales: système central et système péripherique. In: Guimelli C, editor. Structures et transformations des representations sociales. Neuchatel: Delachaux et Niestlé; 1994. p. 73-84.

8. Jodelet D. Représentations sociales: un domaine en expansion. Paris: PUF; 1989.

9. Fonseca LS, Martins G. Curso de estatística. São Paulo: Atlas; 1996.

10. Gil AC. Métodos e técnicas de pesquisa social. São Paulo: Atlas; 1987.

11. Haznier L. Estatística aplicada à economia e administração. São Paulo: McGraw Hill do Brasil; 1982.

12. Bardin L. Análise de conteúdo. Lisboa: Edições 70; 1977.

13. Sá CP. Núcleo central das representações sociais. Petrópolis: Editora Vozes; 1996.

14. Vieira S. Introdução à bioestatística. Rio de Janeiro: Campus; 1980.

15. Beaufils B. Statistiques appliquées à la psychologie: statistiques descriptives. Paris: Bréal; 1996.

16. Abric J-C. A theoretical and experimental approach to the study of social representation in a situation of interation. In: Farr RM, Moscovici S, editors. Social representations. Cambridge: Cambridge University Press; 1984. p. 169-83.

17. FARMANIA. O mercado farmacêutico brasileiro: a sua evolução recente, mercados e preços. http: //www.farmania.hpg.ig.com.br/mercado/mercadobrasileiro.htm (acessado em 19/Jan/2003).

18. Brasil. Relatório da CPI-Medicamentos: relatório final da comissão parlamentar de inquérito destinada a investigar os reajustes de preços e a falsificação dos medicamentos, materiais hospitalares e insumos de laboratórios. Brasília: Câmara dos Deputados; 2000.

19. Brasil. Medida provisória no 2.063 de 18 de dezembro de 2000. Define normas de regulação para o setor de medicamentos, institui a Fórmula Paramétrica de Preços de Medicamentos - FPR, cria a Câmara de Medicamentos e dá outras providências. http://www.presidencia.gov.br/ccivil_03/MPV/2063.htm (acessado em 16/Fev/2003).

20. Ministério da Economia, Fazenda e Planejamento. Portaria o 37, de 11 de maio de 1992. http: //www.abcfarma.org.br/portaria37.htm (acessado em 16/Fev/2003).

21. Brasil. Medida provisória no $2.138-2$ de 28 de dezembro de 2000. Define normas de regulação para o setor de medicamentos, institui a Fórmula Paramétrica de Preços de Medicamentos - FPR, cria a Câmara de Medicamentos e dá outras providências. http://www.presidencia.gov.br/ccivil_03/MPV/2063.htm (acessado em 16/Fev/2003).

22. Brasil. Lei no 10.213 de 27 de março de 2001. Define normas de regulação para o setor de medicamentos, institui a Fórmula Paramétrica de Preços de Medicamentos - FPR, cria a Câmara de Medicamentos e dá outras providências. http://www. planalto.gov.br/ccivil_03/Leis/LEIS_2001/L10213 .htm (acessado em 16/Fev/2003).

23. Brasil. Medida provisória no 123 de 26 de junho de 2003. Define normas de regulação para o setor farmacêutico, cria a Câmara de Regulação do Mercado de Medicamentos - CMED, altera a Lei no 6.360 , de 23 de setembro de 1976, e dá outras providências. http://www.anvisa.gov.br/monito$\mathrm{ra} / \mathrm{cmed} /$ legis/mp/123_03.htm (acessado em 28/ Nov/2003).

24. Departamento de Atenção Básica, Secretaria de Políticas de Saúde, Ministério da Saúde. Política Nacional de Medicamentos. Brasília: Ministério da Saúde; 2001.

25. Silva LBL, Santana DP. Repertório de excipientes com efeito notório. Infarma 2002; 15:67-70.

26. Even-Adin D, Muylder JA, Sternon J. Generics: similarities, bioequivalence but no conformity. J Pharm Belg 2002; 57:14-20.

27. Castanedo-Cázares JP, Quistán-Galván J, TorresAlvarez B, Torres-Ruvalcaba A, Moncada B. Estudio del efecto antiinflamatorio de un corticosteroide tópico: marca reconocida versus genéricos. Gac Med Mex 2001; 137:311-4.

28. Besag FM. Is generic prescribing acceptable in epilepsy? Drug Saf 2000; 23:173-82.

29. Tura LFR. AIDS e estudantes: a estrutura das representações sociais. In: Jodelet D, Madeira M, organizadores. AIDS e representações sociais: a busca dos sentidos. Natal: EDUFRN; 1998. p. 12154 .

Recebido em 25/Abr/2003

Versão final reapresentada em 03/Dez/2003 Aprovado em 18/Ago/2004 